\title{
A hand-held row-column addressed CMUT probe with integrated electronics for volumetric imaging
}

Engholm, Mathias; Christiansen, Thomas Lehrmann; Beers, Christopher; Bagge, Jan Peter; Moesner, Lars Nordahl; Bouzari, Hamed; Lei, Anders; Berkheimer, Michael; Stuart, Matthias Bo; Jensen, Jørgen Arendt

Total number of authors:

11

Published in:

Proceedings of 2015 IEEE International Ultrasonics Symposium

Link to article, DOI:

10.1109/ULTSYM.2015.0143

Publication date:

2015

Document Version

Peer reviewed version

Link back to DTU Orbit

Citation (APA):

Engholm, M., Christiansen, T. L., Beers, C., Bagge, J. P., Moesner, L. N., Bouzari, H., Lei, A., Berkheimer, M., Stuart, M. B., Jensen, J. A., \& Thomsen, E. V. (2015). A hand-held row-column addressed CMUT probe with integrated electronics for volumetric imaging. In Proceedings of 2015 IEEE International Ultrasonics Symposium IEEE. https://doi.org/10.1109/ULTSYM.2015.0143

\section{General rights}

Copyright and moral rights for the publications made accessible in the public portal are retained by the authors and/or other copyright owners and it is a condition of accessing publications that users recognise and abide by the legal requirements associated with these rights.

- Users may download and print one copy of any publication from the public portal for the purpose of private study or research.

- You may not further distribute the material or use it for any profit-making activity or commercial gain

- You may freely distribute the URL identifying the publication in the public portal 


\title{
A hand-held row-column addressed CMUT probe with integrated electronics for volumetric imaging
}

\author{
Mathias Engholm*, Thomas Lehrmann Christiansen*, Christopher Beers ${ }^{\S}$, Jan Peter Bagge ${ }^{\ddagger}$, \\ Lars Nordahl Moesner ${ }^{\ddagger}$, Hamed Bouzari ${ }^{\dagger}$, Anders Lei*, Michael Berkheimer ${ }^{\S}$, Matthias Bo Stuart ${ }^{\dagger}$, \\ Jørgen Arendt Jensen ${ }^{\dagger}$, and Erik Vilain Thomsen* \\ *Department of Micro and Nanotechnology, Technical University of Denmark, DK-2800 Kgs. Lyngby, Denmark \\ ${ }^{\dagger}$ Center for Fast Ultrasound Imaging, Department of Electrical Engineering, Technical University of Denmark, \\ DK-2800 Kgs. Lyngby, Denmark \\ ${ }^{\ddagger}$ BK Ultrasound, Analogic Ultrasound Group, DK-2730 Herlev, Denmark. \\ ${ }^{\S}$ Sound Technology Inc, Analogic Ultrasound Group, PA-16801, USA.
}

\begin{abstract}
A $3 \mathrm{MHz}, \lambda / 2$-pitch $62+62$ channel row-column addressed 2-D CMUT array designed to be mounted in a probe handle and connected to a commercial BK Medical scanner for real-time volumetric imaging is presented. It is mounted and wire-bonded on a flexible PCB, which is connected to two rigid PCBs with pre-amplifiers for driving the cable to the scanner. The array and PCBs are encapsulated in a 3-D printed handle, and a grounded shielding layer and silicone coating is applied to the front-side of the array for physical and electrical isolation. The handle is assembled together with a 192-channel coaxial cable that connects it to the ultrasound scanner, which supplies the probe with a $190 \mathrm{~V}$ DC bias voltage and up to $\pm 75 \mathrm{~V}$ AC excitation voltage. The probe was successfully connected to a BK3000 scanner and used as two decoupled 1-D phased arrays. Volumetric imaging was demonstrated using the experimental SARUS scanner with 132 volumes/sec.
\end{abstract}

\section{INTRODUCTION}

In recent years, time resolved 3-D (4-D) imaging has received considerable interest, since it has several advantages over conventional 2-D imaging. Therefore, modern 2-D arrays are made with pre-beamformers in the handle as e.g. the X6-1 PureWave xMATRIX Array from Phillips (Eindhoven, Holland). By performing some of the beamforming in the probe itself, it is possible to have much fewer channels funneled to the scanner [1]. However, pre-beamformers in the probe requires power-consuming electronics, which is expensive and causes heating of the probe.

Recently, row-column addressed arrays have attracted some attention as an alternative to the matrix arrays, since they offer volumetric imaging with a greatly reduced amount of electrical connections [2], [3]. The 2-D array is essentially comprised of two orthogonal 1-D arrays where transmit focusing is performed in a line in one dimension, while receive focusing is performed in a line in the orthogonal dimension. In this way, the number of electrical connections can be reduced from $\mathrm{N}^{2}$ to $2 \mathrm{~N}$. Row-column addressed arrays have been demonstrated both using PZT [4] and CMUT [5]-[7] technology, but have never been integrated into a probe.

This paper presents the development of a row-column addressed CMUT probe for volumetric imaging which has been designed to be used on a commercial BK3000 scanner from BK Ultrasound (Herlev, Denmark). The scanner is made for conventional 2-D imaging, but due to the low channel count of the row-column addressed probe, the probe and scanner can be directly interfaced.

\section{Design, FABricAtion, Assembly, And Electronics}

\section{A. Array Design}

The transducer design is based on a previously tested design [7]. It is designed for being mounted in a handle and connected to a commercial BK Medical scanner for real-time volumetric imaging. The CMUT array is a $62+62$ element array designed with a $\lambda / 2$-pitch and an operating frequency of $3 \mathrm{MHz}$. The probe uses the built-in $190 \mathrm{~V}( \pm 95 \mathrm{~V})$ DC power supply and up to $\pm 75 \mathrm{~V}$ AC excitation voltage of a BK3000 scanner from BK Ultrasound.

\section{B. Fabrication of CMUTs}

The fabrication of the CMUT array is based on the wellknown LOCOS process (LOCal Oxidation of Silicon), and is a micro-fabrication process where silicon is selectively oxidized. To perform the LOCOS, areas not meant to be oxidized have to be covered by a material that blocks the diffusion of oxygen. The by far most common material used as the diffusion mask is silicon nitride, $\mathrm{Si}_{3} \mathrm{~N}_{4}$, which is capable of tolerating the high temperature oxidizing environment for a reasonably long time. This technique has previously been used to produce the CMUT cavities [8] and is here used to both create the CMUT cavities and to electrically insulate the bottom electrodes as described in the following.

The row-column CMUT array is fabricated using cleanroom technology and is a nine step process as illustrated in Fig. 1 with four lithography steps. The starting point is a siliconon-insulator (SOI) wafer with a $20 \mu \mathrm{m}$ device layer for the bottom electrode. First, a silicon dioxide layer is thermally grown using a dry oxidation upon which a silicon nitride is deposited followed by a poly-silicon layer (step 1). Using a conventional photolithographic process and a wet etch, the poly-silicon is structured to define the cavity pattern (step 2a). The poly-silicon pattern is then transferred to the silicon nitride using a hot phosphoric acid etch. The poly-silicon is 


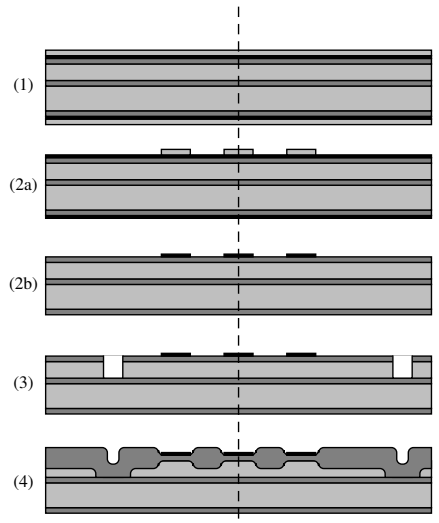

$\square \mathrm{Si}$

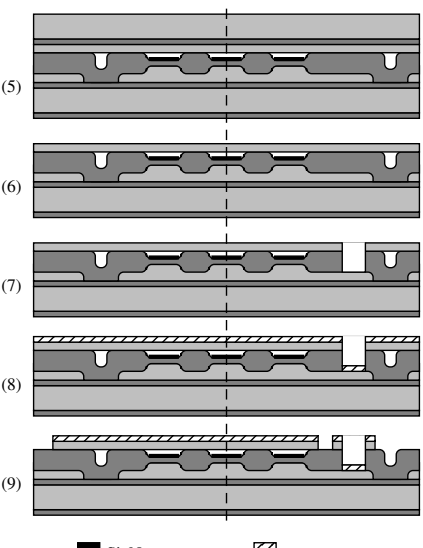

$\bigotimes \mathrm{Al}$
Fig. 1. Process flow of the cleanroom fabrication. The dashed line separates the layer composition comprising the top electrode (to the left of the line) and the bottom electrode (to the right of the line).

stripped using a reactive ion etch (RIE) (step 2b). Next, the insulating trenches are defined. This is done using an RIE process to etch the oxide, followed by a deep reactive ion etch (DRIE) to etch the silicon (step 3). The high selectivity between the silicon and the oxide will stop the etch at the buried oxide (BOX). The cavities are now defined using a LOCOS process in a wet atmosphere (step 4). Fig. 2 shows the cavities and the insulating trench between the bottom electrodes. A zoom in of the corner of the bottom electrode shows that the electrode is completely covered by oxide. This helps to increase the robustness of the device, since there is no risk of short-circuiting the bottom electrodes.

A new SOI wafer, with a device layer corresponding to the desired plate thickness, is then bonded to the bottom electrode wafer (step 5). After annealing, the handle layer (silicon) of the top SOI wafer is removed in an RIE process and the BOX is removed in a wet oxide etch (BHF) (step 6). Hereafter, the openings to the bottom electrodes are etched using a DRIE etch of silicon followed by an inductively coupled plasma etch of oxide (step 7). Metal (titanium and aluminum) for contacts are then deposited using an e-beam evaporation (step 8). The metal and the underlying silicon plate are structured to define the top elements, using an RIE and DRIE etch, respectively (step 9). Finally, the wafer is ready to be diced and mounted.

\section{Probe Assembly}

The probe is composed of five different parts as shown in Fig. 3. The CMUT array is mounted and wire-bonded on a flexible printed circuit board (PCB) containing a rigid support directly beneath the array. A glob-top dam was applied around the array such that the height was higher than the wire-bonds. This was done in order to ensure protection of the wire-bonds against mechanical stresses when pressing the probe against an object. The array was hereafter cleaned with acetone/IPA before it was coated using room temperature vulcanized (RTV) silicone, which provided electrical insulation. Before curing of the RTV, an aluminized polymer film $(12.5 \mu \mathrm{m}$ polypropylene with a sub-micron thick aluminum layer) was applied and

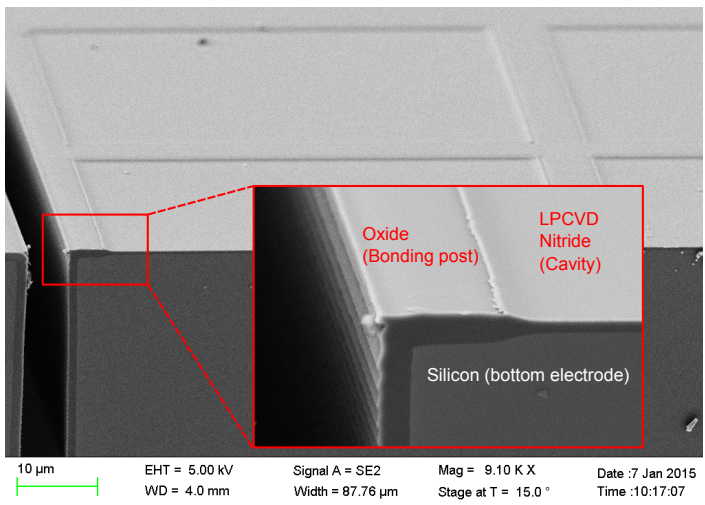

Fig. 2. Scanning electron micrograph showing a cross-section of a fabricated chip before wafer bonding.

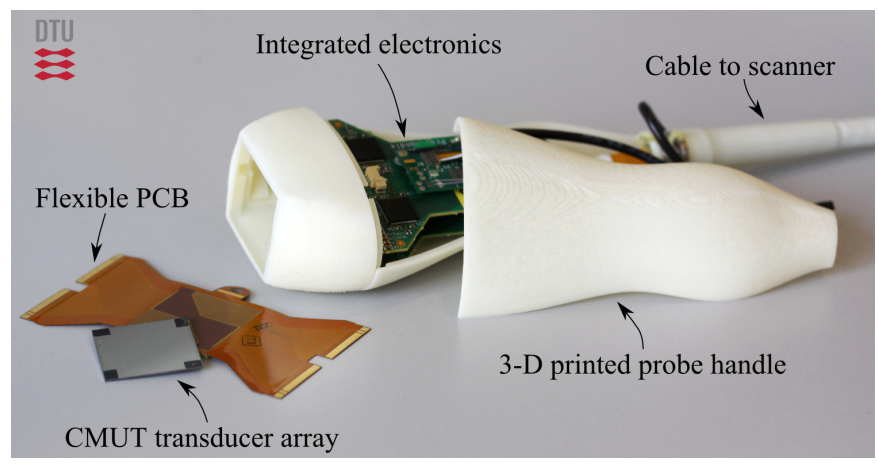

Fig. 3. Image showing the main components of the probe.

planarized using a piece of glass. The aluminum foil was applied to provide a ground shielding layer on top of the array for both patient safety and electromagnetic shielding. The array was then mounted in the nose piece of the 3-D printed probe handle and a second layer of RTV was applied to a final thickness of $1.5 \mathrm{~mm}$ and leveled such that no lens effect occurred. The connectors of the flex PCB were then connected to two rigid PCBs with pre-amplifiers, and a 192-channel coaxial cable was attached to the latter. The entire probe electronics was wrapped in a shielding foil and connected to the shielding foil that was applied to the array. This shield was then connected to the shield of the coaxial cable and hereby also the reference ground of the scanner. Finally, the two 3-D printed parts constituting the handle were assembled to complete the row-column addressed CMUT probe.

\section{Interconnect Electronics}

The interconnect electronics is the same as used by Christiansen et al. [7], however the MAX4805A (Maxim Integrated, San Jose, CA, USA) has been exchanged with the AHV1301 (Analog Devices, Norwood, Ma, USA). An overview of the electronics is given below.

The two electronics PCBs in the probe contain preamplifiers with a $0 \mathrm{~dB}$ voltage gain, and they work as high impedance buffer amplifiers that removes the electrical load of the cable on the CMUT array. The PCBs also contain passive high pass filters for separating the DC bias voltage from the AC voltage 


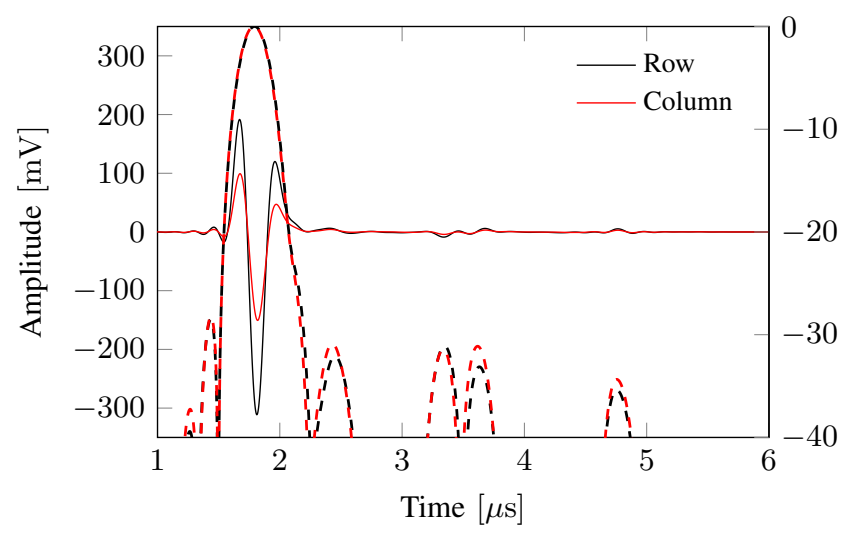

Fig. 4. Average impulse response (in $\mathrm{mV}$ ) and normalized envelope (in $\mathrm{dB}$ ) of the probe elements.

signals. The electronics is designed to allow all elements to be used interchangeably as either transmitters or receivers. An elaborate description of the interconnect electronics can be found in [7].

\section{CharaCterizATION}

After assembly, the probe was characterized acoustically. The pulse-echo response of each element was measured using a XCDR II Pulse Echo Test System by emitting with one element at a time against a plane steel reflector placed $25 \mathrm{~mm}$ away in DI water. The elements were actuated with a square pulse and the received signal was then de-convolved with the excitation pulse to obtain the impulse response.

In Fig. 4, the average impulse response and its envelope are shown for the rows and columns, respectively. In this setup, the rows correspond to the top electrodes of the CMUT array and the columns to the bottom electrodes. Note that the signal of the columns are roughly half of the columns. This is due to capacitive coupling to the substrate of the bottom SOI wafer [5], [7]. When a signal is received on the bottom electrode, the substrate will appear grounded, since the signal may follow a path through the substrate and couple to ground through the neighboring bottom elements. Even though the substrate has an non-negligible impedance, the parallel coupling of the bottom electrodes results in a relatively low-impedance path to ground, resulting in reduction of the signal. It should however be noted that even though the signal amplitude are different, the envelopes are almost identical.

Two extra lobes after the main lobe around $-30 \mathrm{~dB}$ are observed at starting times of $3.2 \mu \mathrm{s}$ and $4.7 \mu \mathrm{s}$. The time difference between these two lobes are $1.5 \mu$ s corresponding to the difference between the main lobe and the first secondary lobe. This could suggest reflections within the probe. The coating material of the array is RTV which has an acoustic velocity of $1.0 \mathrm{~mm} / \mu \mathrm{s}$. The reflections indicate that a reflecting structure is present at a distance of $0.75 \mathrm{~mm}$, corresponding to the shielding foil covering the array.

Fig. 5 shows the average spectra for the rows and the columns. The center frequency at $3.03 \mathrm{MHz}$ and the $-6 \mathrm{~dB}$

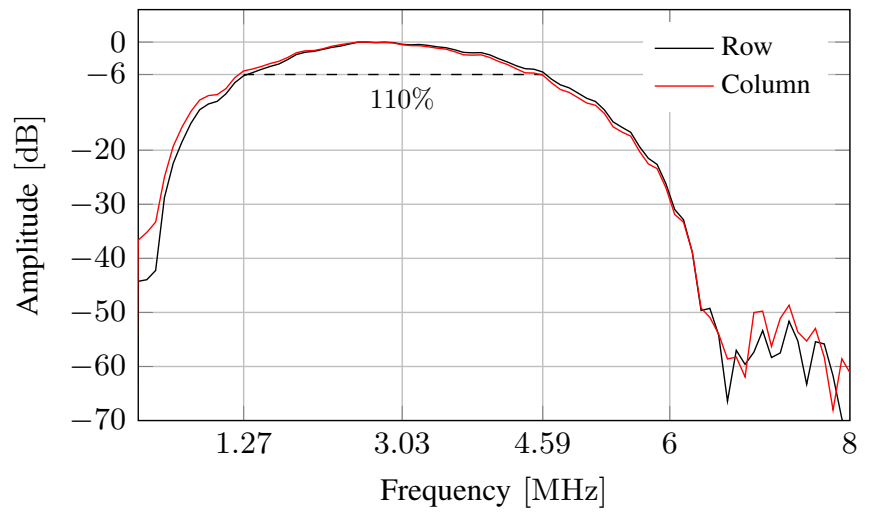

Fig. 5. The impulse response spectra are shown for the probe elements. The center frequency and the fractional bandwidth are indicated on the plot.

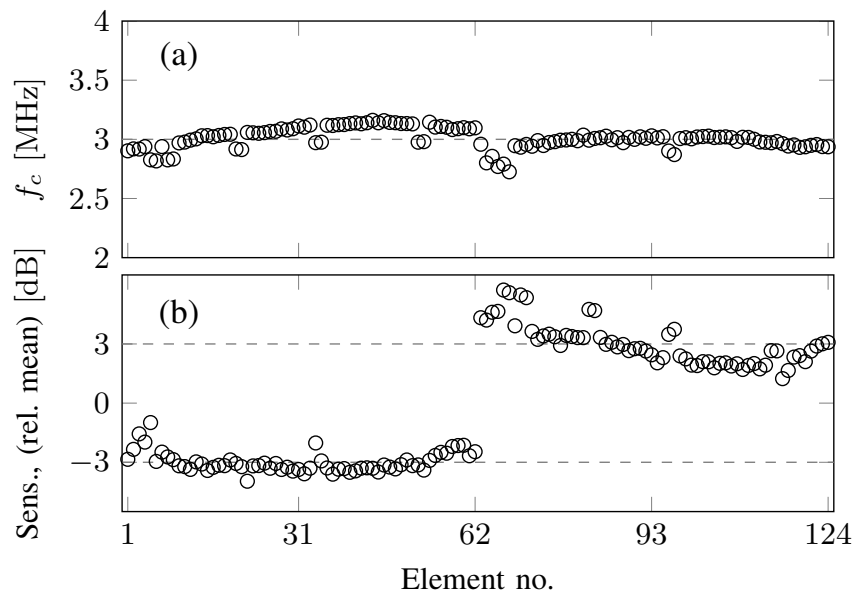

Fig. 6. Center frequency (a) and sensitivity relative to the mean sensitivity (b) across the probe. Element number from 1-62 corresponds to the columns and $63-124$ to the rows.

fractional bandwidth relative to the center frequency are indicated on the plot.

Fig. 6 shows the center frequency (a) and the sensitivity (b) of each element across the array, where element number 1-62 corresponds to the columns and 63-124 to the rows. A "smooth" variation of the resonance frequency across the element is seen indicating that the variation is mostly caused by the nonuniformity of the silicon plate originating from the device layer of the SOI wafer. The sensitivity is plotted relative to the mean sensitivity and the performance is relatively stable over the rows and columns independently. A difference of $6 \mathrm{~dB}$ is observed between the rows and columns elements due to the substrate coupling as discussed previously.

\section{IMAGING}

Volumetric imaging using the commercial BK3000 scanner could not be demonstrated, because the beamforming algorithm had not been implemented on the scanner at the time of acquisition. However, to prove the compatibility with the scanner, the BK3000 scanner was set to treat the probe as two decoupled 1-D phased arrays. This enabled real-time phased array imaging simultaneously in both the azimuth and 


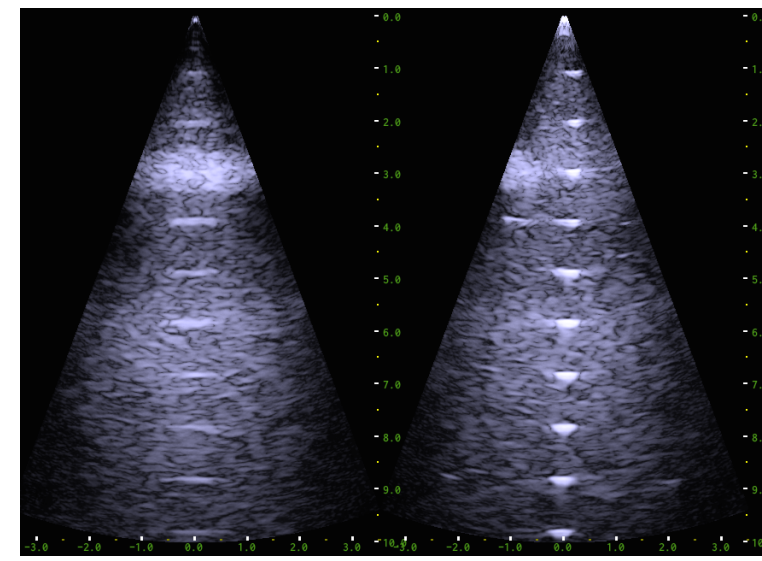

Fig. 7. A snapshot of the real-time image display from the BK3000 scanner showing two cross-planes of a tissue-mimicking phantom containing wires.

elevation directions. All elements in each 1-D array was used for transmission and receiving, the transmit focusing was set at $5 \mathrm{~cm}$ and steered in a sector angle of $45^{\circ}$, while a dynamic receive focusing was employed.

A snapshot of a real-time image display from the scanner is shown in Fig. 7. The images generated from the rows and columns are shown side-by-side. A tissue-mimicking phantom containing wires is imaged down to a depth of $10 \mathrm{~cm}$, the wires running parallel to the image plane in the left figure and perpendicular in the right. A hyperechoic cylinder is located at a depth of $3 \mathrm{~cm}$. The cylinder is seen across the whole image as it consist of point scatters. As opposed to this, the wires reflect the sound away and are, thus, only seen in the center.

To show the volumetric imaging capability of the probe, a wire phantom was imaged using the SARUS experimental scanner [9] with 132 volumes per second. The wire phantom is composed of multiple wires parallel to each other at different depths. Fig. 8 shows a 3-D volumetric rendering of the 21 wires. The image is acquired synthetically with single element emissions using a custom designed delay-and-sum beamformer [10].

\section{CONClusion}

This paper presented the development of the first ever demonstrated row-column addressed CMUT ultrasound probe. It was designed to be used with a commercial BK3000 scanner from BK Ultrasound (Herlev, Denmark). The scanner is made for conventional 2-D imaging, but due to the low channel count of the row-column addressed probe, the probe and scanner can be directly interfaced. A solution with a flexible mounting PCB and two rigid amplifier PCBs were used to mount the array and interface it to the scanner cable via buffer amplifiers. The array and electronics were electrically shielded with a metal foil, and the array was coated with a silicone coating before the entire probe was encapsulated in a 3-D printed handle. The compatibility with the BK3000 scanner was demonstrated using the probe as two decoupled 1-D phased arrays. Volumetric images was demonstrated using the experimental SARUS scanner (since the beamforming
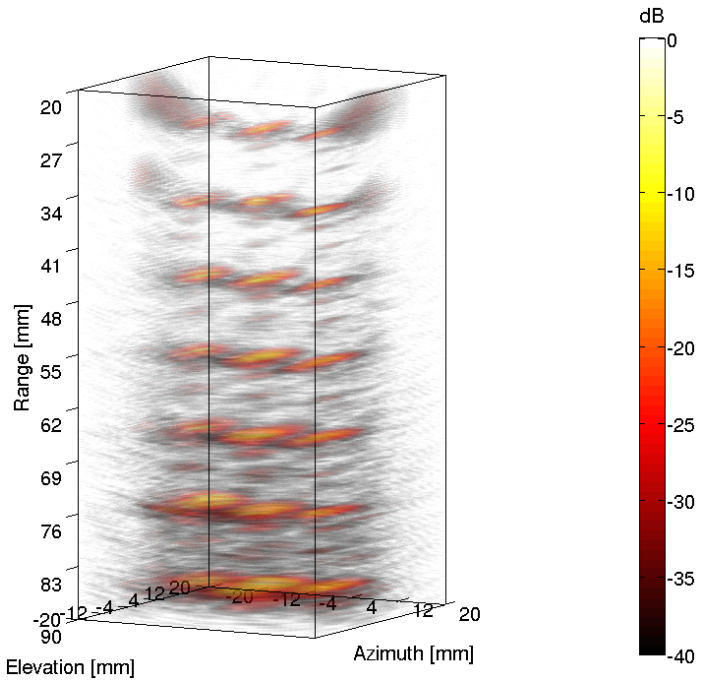

Fig. 8. Volumetric rendering of a wire phantom acquired with the CMUT row-column addressed probe.

algorithm was not yet implemented on the BK3000 scanner).

\section{ACKNOWLEDGEMENT}

This work is financially supported by the Danish National Advanced Technology Foundation (82-2012-4) and by BK Ultrasound.

\section{REFERENCES}

[1] J. D. Fraser, "Ultrasonic diagnostic imaging system with dynamic microbeamforming," Apr. 23 2002, US Patent 6,375,617.

[2] C. E. Demore, A. W. Joyce, K. Wall, and G. R. Lockwood, "Real-time volume imaging using a crossed electrode array," IEEE Trans. Ultrason., Ferroelec., Freq. Contr., vol. 56, no. 6, pp. 1252-1261, 2009.

[3] M. F. Rasmussen and J. A. Jensen, "3-D ultrasound imaging performance of a row-column addressed 2-D array transducer: A measurement study," in Proc. IEEE Ultrason. Symp., 2013, pp. 1460-1463.

[4] C. H. Seo and J. T. Yen, "A 256 x 256 2-D array transducer with rowcolumn addressing for 3-D rectilinear imaging," IEEE Trans. Ultrason., Ferroelec., Freq. Contr., vol. 56, no. 4, pp. 837-847, 2009.

[5] A. S. Logan, L. L. Wong, A. Chen, J. T. Yeow et al., "A 32 x 32 element row-column addressed capacitive micromachined ultrasonic transducer," IEEE Trans. Ultrason., Ferroelec., Freq. Contr., vol. 58, no. 6, pp. 1266$1271,2011$.

[6] A. Sampaleanu, P. Zhang, A. Kshirsagar, W. Moussa, and R. Zemp, "Top-orthogonal-to-bottom-electrode (TOBE) CMUT arrays for 3-D ultrasound imaging," IEEE Trans. Ultrason., Ferroelec., Freq. Contr., vol. 61, no. 2, pp. 266-276, 2014.

[7] T. L. Christiansen, M. F. Rasmussen, J. P. Bagge, L. N. Møsner, J. A. Jensen, E. V. Thomsen et al., "3-D imaging using row-column-addressed arrays with integrated apodization - part II: transducer fabrication and experimental results," IEEE Trans. Ultrason., Ferroelec., Freq. Contr., vol. 62, no. 5, pp. 959-971, 2015.

[8] K. K. Park, H. Lee, M. Kupnik, and B. T. Khuri-Yakub, "Fabrication of capacitive micromachined ultrasonic transducers via local oxidation and direct wafer bonding," J. Microelectromech. Syst., vol. 20, no. 1, pp. 95-103, 2011.

[9] J. A. Jensen, H. Holten-Lund, R. Nilsson, M. Hansen, U. Larsen, R. Domsten, B. Tomov, M. Stuart, S. Nikolov, M. Pihl, Y. Du, J. Rasmussen, and M. Rasmussen, "SARUS: A synthetic aperture real-time ultrasound system," IEEE Trans. Ultrason., Ferroelec., Freq. Contr., vol. 60, no. 9, pp. 1838-1852, 2013.

[10] M. F. Rasmussen, T. L. Christiansen, E. V. Thomsen, and J. A. Jensen, "3-D imaging using row-column-addressed arrays with integrated apodization - part I: apodization design and line element beamforming," IEEE Trans. Ultrason., Ferroelec., Freq. Contr., vol. 62, no. 5, pp. 947-958, 2015. 